\title{
Usage of Facebook and Twitter by Egyptian Female University Students
}

\author{
Abd El-Reheem Ahmed Solyman Darweesh ${ }^{1}$

\section{Introduction}

Egypt is an apparent leading country in the Arab world with its population, which exceeds 90 million people. At least 30 million of them use computers and Internet. New Technology of smart phones and tablets enable more Egyptian youths to use Internet, so Internet use among Egyptian youth is an everyday activity. Although many studies address Internet uses and its effects on Egyptian, few researches have been done on the effects of social interaction sites on females.

The proposed study focuses on the effects of using Facebook and Twitter has on young female university students in particular areas. The study will be conducted on a sample of 400 female university students in Cairo and Damietta and results will be interpreted in the light of uses and Gratifications Theory.

The study will first focus on the percentage of Egyptian woman using Facebook and Twitter compared to the rest of the Egyptian culture and how that correlates with their demographics. The demographics will be broken down into whether they live in an urban or rural area, their socioeconomic status, living status, and the nature of their study while in school. Secondly, it will focus on the female students' personal assessment of their involvement on Facebook and Twitter and how it relates to the advantages and disadvantages as they see in social media. Lastly, the perspectives of Facebook and Twitter on the students' achievement, interaction between family and friends, relationships with the opposite sex, public

\footnotetext{
${ }^{1}$ Associate Professor of Mass Communication and the head of Mass Communication Department at Damietta University, Egypt
} 
information acknowledgement, contribution to political and social activities, and sleep and eating disorders will be studied.

This study takes a different approach than studies preceding it that focused on effects of Internet use in Egyptian culture. This particular study will focus on the young females of the culture specifically on female university students. Exceeding 90 million people, Egypt is the leading country in the Arab world. With such a large population of at least 30 million utilizing sites such as Facebook and Twitter on their computers, smartphones, and tablets, the data will be sufficient in showing the true effects of social media on the young females of this culture.

\section{Review of the Literature}

A few studies have addressed social network sites SNS in Egypt like most of studies, which we will present here although there are three studies examine many other Arabic countries, and Egypt is included in the study (Hassan 2009; Abd-Ellah 2011; Hassan2012; Bahag 2013).

These studies can be categorized into three different areas: Some researchers focused on internet usage as a whole and its effect on traditional media (Kilany 2007; Abdou 2013), a second team of researchers investigated motives of SNS use (Zakareya (2009); Abd-Elrazek 2011; Asaad 2011 Mansour 2011; Taha 2011; Mohammadein 2012; El-Sayed 2014), the third team of researchers explored positive and negative effects for using SNS (Abd-Ellah 2011; Alheity 2012 ; Bahag 2013; Hussein 2014).

Here we will show for all these studies chronically.

Kilany (2007) conducted a study on a sample of 310 Internet users from Cairo to examine both the effects of Internet on traditional media and if the Internet is a real threat to them. She found that Internet has a negative effect on using traditional media especially the print newspapers. The study also referred to a strong significant relationship between using Internet and relying on it to get information about current events. The study also showed that $33 \%$ of Egyptian youth use Internet daily for more than 3 hours and youth from 15-25 years use Internet more as a source for getting news and information. 
Hassan (2009) surveyed a random multi stages sample of 600 Egyptian and Qatari youth. He found that Facebook, YouTube and MySpace were the most preferred SNS. He also found a significant correlation between the increase in using social networks and youth attitudes to form stable and strong relationships. The study also indicates to a negative correlation between using SNS and both level of real social interaction and the level of study achievement.

Zakareya (2009) interviewed 168 university students from both a Cairo university and British University in Cairo to discover the motives of Facebook users. She found these motives: entertainment, interaction with others, communication amongst friends, meeting new friends, and keeping the relations with old friends. Egyptian youth also use Facebook because of the variety they found in the site activities like viewing pictures and videos, congratulating friends in different occasions, and joining different groups. She concluded that Facebook is a part of everyday life for youth and they find positive effects for Facebook on social effects like communication and social interaction.

Abd-Ellah (2011) tried to find out the factors that affect the usage of Internet among Egyptian and Saudi women. She found agreement among respondents in reasons of preferring the Internet like: personal preference, communicating with others, and spending the free time. She also found negative effects on women when using the Internet like: affecting family relationships, weakening social interaction, fraud, and acquiring negative behaviors.

Abd-Elrazek (2011) conducted a survey on 180 university students from two Egyptian university students as a purposive sample of SNS. She found that Facebook, YouTube, MySpace, Linkedin and Twitter came in the list of used sites in order. The study also identified some reasons for using SNS among youth like: interaction with others and discussing with them, sharing ideas and news, forming new relationships and making friends, spending free time, expressing opinions freely, reading other comments, and sharing in occasions and habits. The study also refer to a positive relationship between usage of social sites 
and all of these consequences: civil participation, self improvement, good relationships with others, improving self learning skills like technical skills and communication skills.

Asaad (2011) attempted to study the relationship between Egyptian youth usage of both YouTube and Facebook and their societal values. He conducted his study on 400 university students. He found that: (1) $81 \%$ of the sample use Internet daily once or more and $74.1 \%$ use Internet from one hour to three hours daily. (2) University students watch entertainment videos on YouTube more and join discussing groups on Facebook more, especially the political groups as an outlet to express both their opinions and points of view. (3) There is a significant relationship between youths' usage of YouTube and Facebook and their societal values as life satisfaction and religiousness. (4) $77.5 \%$ of respondents found negative effects for Facebook like: wasting time, pornographic content, trials of unwilling people to contact them, and some other social problems like cyber bulling and online fraud.

Mansour (2011) tried to find out the effects of university students' usage of Facebook. She interviewed 250 Facebook users from 18-25 years old students to examine motives of usage and its impact. She found that Facebook came first then Twitter and MySpace in the lead of social sites used among youth. The study showed that gender affects motives of Facebook usage and referred to a significant relationship between reasons of using Facebook and the consequences of this usage like: hours spent in using Facebook, entertainment, addiction, wasting time and exposure to undesirable content.

Taha (2011) interviewed 300 Egyptian university students as an available sample of Facebook users to explore their usage for this site. The most important results were: (1) $75.4 \%$ of the sample visit the site daily and from them $48 \%$ use the site more than two hours. (2) As for motives for visiting the site communicating with friends came first, then joining different groups, and viewing pictures of friends on their walls. (3) $88.3 \%$ of the students joined groups on Facebook and friends were the first source for them to know these groups. (4) Egyptian students have more positive attitudes towards Facebook than 
negative effects as it helps them to communicate with their friends, deepening the exist relationships and making them aware of what is happening. (5) There is a significant relationship between heavy usage of Facebook and social trust in others.

Salem (2011) conducted an online survey through mid August to mid October of 2011 to research the role of social media in women's empowerment in the Arab world. 469 responses were gathered from male and females of 22 Arab countries with $62 \%$ of responses coming from women. The data showed that Egyptian women are less likely to use social media because of family and society barriers or stereotypes. $92 \%$ of responses stated that they use social media to get news updates, information, or advice on a range of issues. In regards to expressing social and political views through social media, most Egyptians thought that there would be no negative repercussion for doing so. While Saudi Arabia and the UAE felt that a negative repercussion would be to be held accountable for their views by authorities. $85 \%$ of Egyptian respondents agreed that social media makes it easier for Arab women to express themselves. $83 \%$ of Arab women agreed that social media could enhance Arab women's participation in civil society with $82 \%$ of Egyptian respondents in agreement.

Abd-Elfattah (2012) conducted a study on a purposive study of 200 from Egyptian youth who joined Muslim brothers group after $25^{\text {th }}$ revolution to discover the communication behaviors of the youth of the Muslim brothers movement. She found that all of the sample use Facebook and only $33.7 \%$ of them use Twitter.

Alasdoudy (2012) tried to investigate the role SNS in university students' perception and political participation in $25^{\text {th }}$ January revolution. She conducted her study on a purposeful sample of 400 social sites users from different 4 Egyptian universities and she found that: (1) $87.5 \%$ of students prefer using these sites at home and there is no significant differences between males and females in using SNS. (2) Neither university student studies in nor nature of study (i.e. theoretical or practical) affects student usage of SNS. (3) Socio economic 
status affects students' heave use of SNS. (4) $96.5 \%$ of respondents express their opinions freely and most students think Facebook played an important role in the revolution.

Alheity (2012) also studied the role of SNS in political movement in the Egyptian society and conducted a study on 300 Egyptian university students. He found that Facebook came first then Twitter in the list of most favorite SNS. $69.9 \%$ of students think Facebook played a crucial role in the Egyptian revolution while $16.1 \%$ think Twitter played a role in the revolution. The study also found some good effects for students' usage of SNS: like deepening participation and communicating with others and involvement in society and discussing its problems, while other students refer to bad effects for these sites like: SNS addiction and being vulnerable to electronic crimes.

Hassan (2012) explored the role of SNS in forming the public opinion in five Arabic countries: Egypt, Libya, Tunisia, Syria, and Yamane. He conducted his study on a sample of 500 adults in these countries from 18-60 years old respondents. The study revealed that SNS overcome traditional media in forming the public opinion and is a real threat for them. The study also indicates to a significant relationship between reliance on social sites and attitude towards the Arabian revolutions. Demographics were not found to have an effect on forming attitude towards these revolutions.

Mohammadein (2012) studied the role of SNS in directing the Egyptian public opinion to political events in Egypt. He conducted his study on the Egyptian audience and interviewed 346 respondents. It was found that $86.7 \%$ of respondents use Facebook while $66.5 \%$ use Twitter. The study found that half of the respondents visit these sites because (1) they discuss the important issues and problems in society (2) to express their opinions freely while $43 \%$ visit them to know the latest developments in events. As for motives for using these sites, wasting time and escape came first.

Abdou (2013) interviewed 200 Egyptian university students who use Facebook and Twitter. He found that $93.9 \%$ of youth use Facebook while $66.4 \%$ only use Twitter while 
$68.8 \%$ use TV. He also found that $43.6 \%$ use print newspapers and $40 \%$ use radio. The study also found that there is a significant negative correlation between using both Facebook and Twitter and the usage of traditional media.

Bahag (2013) studied the usage of Arabic youth for SNS in 10 Arab countries including Egypt. He conducted his study on a sample consisting of 230 youth. He found that $67 \%$ of his sample use Internet daily and $97.6 \%$ of them use it at home. Facebook was the first in use as $87 \%$ of sample use it. $72.6 \%$ established romantic relationships with opposite sex.

Hussein (2014) investigated the role of SNS in developing political awareness. She conducted her study on 512 Egyptian youth from $18-35$ years old. The study concluded that $83.8 \%$ of the sample relies on SNS to get information during the $25^{\text {th }}$ January revolution. Facebook comes first in the list of these networks with percentage of $96 \%$ followed by YouTube 55.5\% and then Twitter $29.1 \%$. There are no differences between males and females in using SNS and $75.9 \%$ of youth agree that using such networks affects positively on their political attitudes.

Recently El-Sayed (2014) attempted to examine youth interaction through SNS and conducted a survey on 301 Egyptian youth. She found that: (1) sex, age, and educational level, don't affect times of Facebook usage daily while socio economic status affect this. (2) Females are less than males in putting personal information. (3) There is significant relationship between using Facebook and sharing political news and engaging in discussions with others. (4) There is significant relationship between using Facebook and both of these activities: making new friends and getting information. (5) Youth participate in some activities on Facebook like: co operation with others to adopt campaigns to change bad behaviors in society, donating time and money for charity organizations, working as volunteers, joining pages of different associations, and attending meets for social purposes.

The third-person effect is the label of a hypothesis that Philips Davison further investigated and defined in 1983. Davison (1983) explained this concept as interpreting the behavior of audiences when they tend to perceive that the other 
will be more persuaded by media messages and that it will have a greater effect on others than themselves. The third-person term is incorporated in the theory "because third persons are involved from two different observational standpoints. In the view of those trying to evaluate the effects of a communication, its greatest impact will not be on "me" or "you," but on "them" -the third persons," (Davison, 1983, p.3). According to Davison (1983), people tend to have this perception as they think that others do not have their same experiences in life and therefore media messages will have greater effect on them than themselves.

More recent studies (Paul, Salwen \& Dupagne, 2009; Paradise and Sullivan, 2012; and Schweisberger, Billinson Chock, 2014) were carried out to explore the attributes of the third person perception. Paul, Salwen and Dupagn (2009) mentioned that previous research suggested that third person effect would be most exhibited among college students, as they perceive themselves smarter. However, they concluded that non-college students were found to exhibit third person perception more than college students. In addition, they found that there were some other factors that did not play a role at predicting the third person effect among audiences such as the desirability of the message communicated, the medium through which the message is disseminated, source of the message, and audiences' country (Paul, Salwen \& Dupagn, 2000).

Exploring third-person effect in the context of social media use, Paradise and Sullivan (2012), sought to dwell into the specific effects of Facebook usage on undergraduate students. They found that the students perceived that Facebook has less negative impact on them in terms of personal relationships, future employment, and privacy than their closest friends, younger people, friends in their Facebook network, and Facebook users. Paradise and Sullivan (2012) mentioned that the students might be overrating their relationships with their Facebook network that many would accept friend requests from people they don't know even though it would put their personal information at risk. This was justified that they were feeling 
more protected against any threats on such platforms than others who use Facebook (Paradise and Sullivan, 2012).

Schweisberger, Billinsonistep and Chock (2014) also sought to explore third person perception on framing via Facebook comments on news stories. They concluded that users perceived that news stories that personally relate to them have more effect on them than those stories that are not. Moreover, they found that the users perceived news stories that were less relevant to them as having greater effect on others than themselves (Schweisberger, Billinson

SNS Addiction falls into a category that is known as a cyber-relationship addiction since the main purpose of these sites is for on-and offline relationships (Kuss and Griffiths, 2011). Those struggling with SNS Addiction Disorder may neglect their personal life, be mentally occupied with thoughts of social media, use social media as a form of escapism, their mood may be modified according to their usage, tolerance level will be affected, and will try to conceal their addiction (Young, 1998). Wang, Lee and Hua (2015) state several terms such as media/internet dependency, media addiction, and technological addiction to all explain the dependency of social media in individuals. Though some studies have been done on dependency research, there has been a consensus between scholars that the terms dependence and addiction can be used interchangeably to some extent.

Wang, Lee and Hua (2015) study states that SNS addiction starts out as a "harml cell phones, Internet surfing, or social media and the individual becomes complacent and free of anxiety while performing these habitual activities.

Studies have shown that those with a narcissistic personality tend to be associate Extraverts on the other hand use social media for social enhancement. Studies have shown that those most at risk of developing a SNS Addiction are those that look for a sense of belonging through social media sites such as Facebook or Twitter (Kuss and Griffiths, 2011).

\section{Descriptive Questions and Hypotheses}


In order to advance understanding of this group's use of social networking sites (SNS), a number of descriptive questions were raised. These included:

- How much time do they spend using SNS if they have accounts at all?

- On what platform(s) do they use SNS?

- Do they publish true information on SNS or do they use aliases?

- What specific activities did they participate in on Facebook and Twitter?

- What were their preferred Facebook and Twitter pages?

- What are their motives for SNS usage?

- How important are Facebook and Twitter to a student's life?

- What do the users believe the effects of SNS use are on them?

- Do they exhibit an addiction to Facebook and Twitter? In addition to these descriptive questions, a number of hypotheses were proposed:

- H1: Demographic variables have no significant effect on Facebook and Twitter use among students.

- H2: Demographic variables of students have a significant effect on Facebook and Twitter addiction.

- H3: Demographic variables have a significant effect on students' motives to use Facebook and Twitter.

- H4.There is a significant relationship between importance of Facebook and Twitter importance in students' lives and their addiction to both of them.

- H5. There is a significant relationship between Facebook and Twitter motives of usage and their addiction in students.

- H6. Students tend to perceive negative effects of Facebook and Twitter on others to be stronger than these effects on themselves (Third Person effect) while they tend to perceive positive effects of Facebook and Twitter on others to be weaker than these effects on themselves (First person effect). 


\section{Methodology}

The sample selected for this study consisted of female university students in Cairo and Damietta to represent both urban and rural students. A quota sample of 400 was employed in this study. They were interviewed and were asked to answer a 30-item paper survey instrument and they were encouraged to do so without writing their names or any information about themselves. Data collection process was between February and March 2015. The paper survey contains five sections designed to examine: (1) student' usage and preference for Facebook and Twitter; (2) motives of usage; (3) Facebook and Twitter addiction scale; (4) students' points of view about Facebook and Twitter effects either generally or on themselves compared with others; and (5) their demographics.

\section{Characteristics of the sample}

A total of 400 students answered the questions of the survey; the sample consisted of 200 theoretical students in Arts college and 200 students in Science college both in Cairo University and Damietta University, or $50 \%$ and $50 \%$ of the sample, and students from Cairo university students represent urban students while students from Damietta University represent rural students as they live in villages. Regarding the educational level of students' parents, their fathers' educational levels varied in their educational status, ranging from less secondary school or equivalent $(N=99,24.8 \%$ of the sample) to secondary school graduates and two years study after secondary school but they are not enrolled in university study $(N=110,27.5 \%)$. Of the respondents, $47.8 \%(N=191)$ reported that their fathers had earned university degrees Bachelor's, Master's degree or Ph.D. On the other hand, their mothers' educational level varied, ranging from less secondary school or equivalent $(N=96,24 \%)$ to secondary school graduates and two years study after secondary but they are not enrolled in university study $(N=156,39 \%)$. Of the respondents, $37 \%$ $(N=148)$ reported that their mothers had earned university degrees Bachelor's, Master's degree or Ph.D.

Students also were classified according to their economic status according to their parents' monthly income, travelling 
abroad and purpose of travelling, whether they live in a house they own or renting it, and family possessions. They were then classified according to their socio economic status into low class $(N=145,36.3 \%)$, middle class $(N=144,36 \%)$, and high class $(N=111,27.8 \%)$.

\section{Results}

\section{Descriptive Information}

Facebook and Twitter usage, practiced activities, and preferred pages:

Students were asked first if they have accounts on Facebook and Twitter then they were asked 'How many hours do you use Facebook and Twitter the Internet weekly?' ' On a 3-point scale: 1 (one day or two), 2 (three or four days), 3 (five days or more) then they were asked 'How many hours do you use the Internet daily?' On a 4-point scale: 1 (less than one hour), 2 (one to two hours), 3 (two to three hours), 4 (more than four hours per day).

Most of Respondents reported using Facebook ( $N=384$, $96 \%$ ) while less than third of the sample reported using Twitter $(N=117,29.3 \%)$. Facebook users spend an average of 2.8 hours per day and $34 \%$ of them use it more than three hours each day while the average of Twitter users daily is 1.9 hour and $11.1 \%$ only of them use it each day. Most of the respondents used the Facebook through smartphone $(N=256$, $64 \%)$, this was followed by laptop or notebook ( $N=256,39 \%)$ and desktop computer $(N=110,27.5 \%)$. As for Twitter also Most of the respondents used the Twitter through smartphone $(N=61$, $15.1 \%)$, this was followed by laptop or notebook ( $N=46,11.5 \%)$ and desktop computer $(N=36,9 \%)$. So, results indicate that Facebook usage is more than Twitter use among students and this is obvious as we asked students who use both of Facebook and Twitter. We found that the majority prefer Facebook to Twitter $(N=69,67 \%)$ while a few students prefer Twitter $(N=13$, $12.6 \%)$ we found more students prefer the both two ( $N=21$, $20.4 \%)$.

More than half of Facebook users admit that they put true information and enter Facebook with their real names $(N=225$, $56.3 \%$ ) and fewer students put some personal information on 
their profiles like name or gender only $(N=201,50.3 \%)$ while a few students admit they never do that $(N=23,5.8 \%)$ and more than third put their full information like photos, ages, name, and gender $(N=144,36 \%)$.

As for Twitter users, the situation is rather different. a few students admit that they put true information and enter Twitter with their real names $(N=55,13.8 \%)$ and fewer students put some personal information on their profiles like name or gender only $(N=53,13.3 \%)$, So, while a few students admit they never do that $(N=23,5.8 \%)$ and more than third put their full information like photos, ages, name, and gender $(N=59$, $14.8 \%)$.

Respondents were asked to list their activities while they are on Facebook and Twitter. Responses ranged from 1 (Never) to 3 (Often). Frequency results revealed that the most cited activities were browsing their wall $(M=2.64)$. This was followed by writing or receiving messages $(M=2.58)$; chatting with others $(M=2.55)$, sending congratulations for friends in different occasions $(M=2.43)$, status updating $(M=2.40)$, writing comments for others $(M=2.35)$, browsing friends or others' walls $(M=2.10)$ and news sites $(M=2.33)$, watching or downloading movies or music videos $(M=1.90)$, establishing group pages $(M=1.69)$ and at last playing games $(M=1.65)$.

As for twitter users' activities, the most cited activities were browsing their wall $(M=2.29)$. This was followed by status updating $(M=2.11)$; writing or receiving messages $(M=1.90)$, sending congratulations for friends in different occasions $(M=1.88)$, chatting with others $(M=1.87)$, browsing friends or others' walls $(M=1.85)$ writing comments for others $(M=2.1 .82)$, watching or downloading movies or music videos $(M=1.69)$, and at last playing games and establishing group pages and at last playing games $(M=1.65)$ for each.

Students were asked to list their preferred pages on Facebook and Twitter. For Facebook users the most preferred pages were social ones $(N=235,58.8 \%)$ followed by religious pages $(N=220,55 \%)$, then cultural pages $(N=207,51,8 \%)$, scientific and educational pages $(N=205,51.3 \%)$, medical and health pages $(N=195,48.8 \%)$, art pages $(N=189,47.3 \%)$, 
political pages $(N=151,37.8 \%)$, and at last spot pages $(N=82$, $20.5 \%$ ). As for Twitter, users the most preferred pages were political ones $(N=64,16 \%)$, followed by social ones $(N=51$, $12.8 \%)$, cultural pages $(N=48,12 \%)$, art pages $(N=45,11.3 \%)$, religious pages and scientific and educational pages $(N=38$, $9.5 \%)$ for each of them, medical and health pages $(N=37$, $9.3 \%),(N=205,51.3 \%)$, and at last spot pages $(N=33,8.3 \%)$.

\section{Motives of usage}

To measure students' motives to use Facebook and Twitter, the researchers used the literature of uses and Gratifications theory, which divide motives into instrumental and habitual. Three statements reflect both instrumental and habitual motives were listed and students were asked to mention whether these are reasons for using Facebook and Twitter. Students' answers were ranging from (1) Never to (3) Often. Instrumental statements include: I use Facebook or Twitter to know what is happening around me, to learn and know about life, and for study and research purposes. Habitual statements include: I use Facebook or Twitter to talk to or to date friends of different sex, entertainment and passing time, and I have nothing to do.

As for motives of students' usage of Facebook, we found that students use it for instrumental motives $(M=7.7)$ more than habitual $(M=5.7)$ and the same result is true for Twitter instrumental $(M=6.3)$ and then habitual $(M=5.3)$.

We also found that students use Facebook to maintain the existing friendships $(N=273,68.3 \%)$ more than making new friends $(N=175,43.8 \%)$. They use it to know others' political point of views $(N=157,39.3 \%)$ more than expressing their points of view $(N=119,29.8 \%)$. On the other hand, students use Twitter most to know others' point of views first $(N=69,17.3 \%)$, followed by maintaining the existing friendships $(N=55,13 \%)$, making new friends and expressing their point of views $(N=51$, $12.8 \%$ ) for each.

\section{Facebook and Twitter's importance in students' life}

To measure the importance of Facebook and Twitter in students' life the researchers used seven statements that include intensive importance of Facebook and Twitter in the life 
of students. Subjects responded to these items with a Likert type scale ranging from (1) Never to (3) Often. Chronbach's alpha for online risks measurement is $(0.735)$ for Facebook and (0.786) for Twitter. These statements include: Facebook or Twitter is a very important part of my daily life, I feel I am an important part of Facebook or Twitter, I feel sorry when I can't access Facebook or Twitter, I will feel anger and sorrow if Facebook or Twitter is closed, I am proud if others know that I am Facebook or Twitter user, usage of Facebook or Twitter affects negatively other activities in my daily life, and I am connected to Facebook or Twitter as long as I am awake.

Facebook and Twitter effect on female university students

Subjects responded to 6 statements and were asked to show their agreement or refusal to them and their answers were ranging from (1) disagree to (3) agree.

As for the effects of Facebook, students agree that Facebook increases students' knowledge of what is happening around them and makes them know a lot about political issues $(M=2.66)$, make students contribute in useful political and social activities $(M=2.58)$, affects negatively on students' relationships with their families $(M=2.40)$, affects positively on their study achievements in university $(M=2.36)$, makes students have disorders in sleep or nutrition $(M=2.35)$, and makes students have romantic relationships with other sex $(M=2.20)$.

Students agree that Twitter increases students' knowledge of what is happening around them and makes them know a lot about political issues $(M=2.42)$, make students contribute in useful political and social activities $(M=2.35)$, affects negatively on students' relationships with their families and makes students have disorders in sleep or nutrition $(M=2.15)$, for each, affects positively on their study achievements in university $(M=2.12)$, and makes students have romantic relationships with other sex $(M=1.91)$.

Perceiving Facebook and Twitter effects on self and others

Perceiving Facebook and Twitter effects on self and others were measured by asking students about positive and negative effects of Facebook and Twitter on self and on others. 
Subjects responded to a series of questions with a Likert type scale ranging from (1) very weak to (5) very strong.

Most Facebook users see it has more positive effects than negative effects $(N=141,36.7 \%)$ while fewer respondents see the opposite $(N=96,25 \%)$ and more than third see both negative and positive effects for Facebook are equal $(N=137$, 38.3\%). Most respondents find that Facebook has more positive effects on themselves $(M=3.6)$ than on others $(M=3.2)$, while this result is reversed in relation to negative effects as most subjects see Facebook has more negative effects on others $(M=3.5)$ than on themselves $(M=2.6)$.

Most Twitter users see it has more positive effects than negative effects $(N=53,45.3 \%)$ while fewer respondents see the opposite $(N=15,12.8 \%)$ and nearly half the sample see both negative and positive effects for Twitter are equal ( $N=49$, 41.9\%). Most respondents see Twitter has more positive effects on them selves $(M=3.4)$ than on others $(M=3.1)$, while this result is reversed in related to negative effects as most subjects see Twitter has more negative effects on others $(M=3.05)$ than on themselves $(M=2.3)$.

\section{Facebook and Twitter addiction}

20 items that included statements that reflect addictive behaviors while using Facebook or Twitter measured students' addiction to Facebook or Twitter. Subjects responded to these statements with a Likert type scale ranging from (1) Never to (3) Often. The items were then factored by principal components analysis with varimax rotation. The factor solution yielded four factors (physiological and psychological involvement, loss of time control, spending long hours and bad grades and performance in university) with greater than eight eigenvalue and explained (57.643per cent) of the total variance (see Table 1). Chronbach's alpha for Facebook addiction is (0.903). As for Twitter The factor solution yielded four factors (losing time and preferring Twitter, symptoms of Twitter long use, adoring Twitter and interest in Twitter activities) with greater than eight eigenvalue and explained (62.859percent) of the total variance (see Table 1). Chronbach's alpha for Facebook addiction is (0.914). 
As for Facebook Subjects responded to 20 statements each one with a Likert-type scale ranging from (1) Never to (3) Often and they were asked to tell if this happens to them. The factor solution yielded four factors (physiological and psychological involvement, spending long hours, loss of time control, and bad grades and performance in university):

Factor 1 (physiological and psychological involvement,) explained $35.51 \%$ of the total variance with an eigenvalue of 7.1. The factor is loaded with 'I prefer the enjoyment with Facebook more than enjoyment with real people', 'I make new relationships through Facebook', 'I keep my privacy as a secret when I was asked about what I am doing on Facebook', 'I feel anxious in my life because of Facebook use', 'life is empty, boring, and happiness free without Facebook' and 'I am thinking about Facebook when I am not using it', 'I try to hide amount of time I spend on Facebook', 'I prefer to spend more time with Facebook to going out with others', and 'I feel depressed, nervous and bad tempered when I am not allowed to be on Facebook'.

Factor 2 (loss of time control) explained 6.3 per cent of the total variance with 1.3 eigenvalue. The factor is loaded with 'I spend more time with Facebook than I intended', 'I neglect house work to stay more time with Facebook', and 'I check my Facebook account before doing anything else', and 'I miss some hours of sleeping as I stay awake on Facebook until late at night',

Factor 3 (spending long hours) explained $6.04 \%$ of the total variance with an eigenvalue of 1.2 The factor is loaded with 'people who are around me complain because of long time I spent with Facebook', 'I find myself taking part in Facebook activities again when I return to it I leave Facebook', 'I feel sleepy and yawn when I am on Facebook', 'I say to myself I will spend just minutes on Facebook but I can't leave it', and 'I try to reduce hours spent on Facebook but I fail'.

Factor 4 (bad grades and performance in university) explained 5.03 per cent of the total variance with 1.005 eigenvalue. The factor is loaded with 'my grades decrease in 
university because of Facebook use and 'my performance is affected because of Facebook use'.

Table 1 Factor Analysis of Facebook addiction

\begin{tabular}{|c|c|c|c|c|}
\hline Addiction statements & $\begin{array}{c}\text { Factor } \\
1\end{array}$ & Factor2 & Factor3 & Factor4 \\
\hline $\begin{array}{l}\text { I prefer the enjoyment with Facebook more } \\
\text { than enjoyment with real people }\end{array}$ & .682 & & & \\
\hline I make new relationships through Facebook & .514 & & & \\
\hline $\begin{array}{l}\text { I keep my privacy as a secret when I was } \\
\text { asked about what I am doing on Facebook }\end{array}$ & .600 & & & \\
\hline $\begin{array}{c}\text { I feel anxious in my life because of Facebook } \\
\text { use }\end{array}$ & .544 & & & \\
\hline $\begin{array}{l}\text { life is empty, boring, and happiness free } \\
\text { without Facebook' }\end{array}$ & .469 & & & \\
\hline $\begin{array}{l}\text { I am thinking about Facebook when I am not } \\
\text { using it' }\end{array}$ & .488 & & & \\
\hline $\begin{array}{l}\text { I try to hide amount of time I spend on } \\
\text { Facebook }\end{array}$ & .548 & & & \\
\hline $\begin{array}{l}\text { I prefer to spend more time with Facebook to } \\
\text { going out with others' }\end{array}$ & .730 & & & \\
\hline $\begin{array}{l}\text { I feel depressed, nervous and bad tempered } \\
\text { when I am not allowed to be on Facebook' }\end{array}$ & .621 & & & \\
\hline $\begin{array}{l}\text { I spend more time with Facebook than I } \\
\text { intended }\end{array}$ & & .872 & & \\
\hline $\begin{array}{l}\text { I neglect house work to stay more time with } \\
\text { Facebook }\end{array}$ & & .690 & & \\
\hline $\begin{array}{l}\text { I check my Facebook account before doing } \\
\text { anything else }\end{array}$ & & .455 & & \\
\hline $\begin{array}{l}\text { I miss some hours of sleeping as I stay } \\
\text { awake on Facebook until late at night }\end{array}$ & & .398 & & \\
\hline $\begin{array}{c}\text { people who are around me complain } \\
\text { because of long time I spent with Facebook }\end{array}$ & & & .433 & \\
\hline $\begin{array}{c}\text { I find myself taking part in Facebook } \\
\text { activities again when I return to it I leave } \\
\text { Facebook' }\end{array}$ & & & .754 & \\
\hline $\begin{array}{l}\text { I feel sleepy and yawn when I am on } \\
\text { Facebook }\end{array}$ & & & .464 & \\
\hline $\begin{array}{c}\text { I say to myself I will spend just minutes on } \\
\text { Facebook but I can't leave it }\end{array}$ & & & .476 & \\
\hline $\begin{array}{c}\text { I try to reduce hours spent on Facebook but I } \\
\text { fail }\end{array}$ & & & .414 & \\
\hline $\begin{array}{l}\text { My grades decrease in university because of } \\
\text { Facebook use }\end{array}$ & & & & .811 \\
\hline $\begin{array}{l}\text { My performance is affected because of } \\
\text { Facebook use }\end{array}$ & & & & .790 \\
\hline
\end{tabular}


As for Twitter Subjects responded to 20 statements each one with a Likert-type scale ranging from (1) Never to (3) Often and they were asked to tell if this happens to them. The factor solution yielded four factors (losing time and preferring Twitter, symptoms of Twitter long use, adoring Twitter, and interest in Twitter activities).

Factor 1 (losing time and preferring Twitter) explained $39.94 \%$ of the total variance with an eigenvalue of 7.9 . The factor is loaded with "I spend more time with Twitter than I intended", 'I neglect house work to stay more time with Twitter', "I prefer the enjoyment with Twitter more than enjoyment with real people', 'I make new relationships through Twitter', 'I miss some hours of sleeping as I stay awake on Twitter until late at night' and 'I say to myself I will spend just minutes on Twitter but I can't leave it'.

Factor 2 (symptoms of Twitter long use) explained $6.5 \%$ of the total variance with an eigenvalue of 1.3 The factor is loaded with 'people who are around me complaing because of long time I spent with Twitter', 'My grades decrease in university because of Twitter use', 'life is empty, boring, and happiness free without Twitter', 'I feel sleepy and yawn when I am on Twitter, 'I try to reduce hours spent on Twitter but I fail', 'I try to hide amount of time I spend on Twitter' and 'My performance is affected because of Twitter use'.

Factor 3 (adoring Twitter) explained 6.01 per cent of the total variance with 1.2 eigenvalue. The factor is loaded with 'I feel anxious in my life because of Twitter use', 'I am thinking about Twitter when I am not using it', 'I prefer to spend more time with Twitter to going out with others' and 'I feel depressed, nervous and bad tempered when I am not allowed to be on Twitter'.

Factor 4 (interest in Twitter activities) explained 5.8 per cent of the total variance with 1.2 eigenvalue. The factor is loaded with 'I check my Twitter account before doing anything else', 'I keep my privacy as a secret when I was asked about what I am doing on Twitter' and 'I find myself taking part in Twitter activities again when I return to it I leave Twitter'. 


\section{Hypotheses}

H1. Demographic variables have no significant effect on Facebook and Twitter use among students.

To test the effect of demographic variables of respondents on Facebook and Twitter use, three separate $t$-tests (university place Cairo or Damietta, nature of faculty theoretical or practical, and residence place city or village) and two separate ANOVA tests were carried out for the other demographic characteristics (educational levels of the respondents' parents and socio economic status).

Results indicated that neither nature of faculty nor residence place had a significant effect on Facebook and Twitter use. The same is true for Cairo and Damietta Univ. concerning Facebook usage. Only Twitter using was significantly affected by the university place $(t=-3.9, d f=115$, $p=0.000)$, Damietta university students use Twitter $(M=2.2)$ more than their counterparts in Cairo University $(M=1.5)$.

Neither the educational level of the fathers ( $F$ $[.997]=2.141, p=0.370)$ nor mothers $(F[1.2]=2.7, p=0.305)$ had a significant effect on Facebook use. Also one-way ANOVAs revealed SES had no significant effect on Facebook use ( $F$ [1.1]=2.6, $p=0.305$ ), and the same result for Twitter use.

H2. Demographic variables of students have a significant effect on Facebook and Twitter addiction.

We compute all degrees each student have on the scale of Facebook and Twitter, then an independent $t$-test revealed that university place had a significant effect on Facebook addiction $(t=-4.51, \mathrm{df}=382, p=0.000)$, since Damietta University students $(M=40.13)$ are addicted to Facebook more than Cairo University students $(M=36.04)$. There is also a significant effect for university place Twitter addiction ( $t=-4.15, \mathrm{df}=115, p=0.000$ ), since Damietta University students $(M=37.36)$ are addicted tovTwitter more Cairo University counterparts $(M=29.2)$.

We also found that residence place had a significant effect on Facebook addiction $(t=-4.51, \mathrm{df}=382, p=0.000)$, since students in villages $(M=40.12)$ are addicted to Facebook more than city students $(M=36.03)$. There is also a significant effect for residence place on Twitter addiction $(t=-502, d f=115$, 
$p=0.000)$, since village students $(M=37.36)$ are addicted to Twitter more than their city counterparts $(M=29.1)$. On the other hand, faculty nature had no effect neither on Facebook nor Twitter addiction.

Students' fathers' educational level has a significant effect on Facebook addiction ( $F[4.2]=2.664, p=0.016)$. Post hoc analysis using the LSD technique indicated that the significant difference could be attributed exclusively to the category of the university degrees holders'. Since the students' fathers who have 'Bachelor, Master or Ph.D.' category was the highest compared to all other categories, with the significant $p$-value at 0.05 . It is followed by the 'Secondary or middle school or more and the 'Respondents' fathers who have less than secondary school certificate'. Person correlation indicated that there was a positive relationship between adolescents' fathers educational level and their Facebook addiction $(r=0.334, p=0.007)$. Nearly the same results for Twitter on the contrary, students' mothers educational levels has neither significant effect on Facebook addiction $(F[.941]=.786, p=0.391)$ nor on Twitter addiction ( $F$ $[1.5]=.95, p=0.225)$.

SES did not have a significant effect on Facebook addiction ( $F$ [2.002] $=.94, p=0.136)$ but it had a significant effect on Twitter addiction ( $F[304]=1.95, p=0.036)$. Post hoc analysis using the LSD technique indicated that the significant difference could be attributed exclusively to the category of the 'low class.' and middle class first then high class.

H3. Demographic variables have a significant effect on students' motives to use Facebook and Twitter.

We compute all degrees each student has on the scale of Facebook and Twitter instrumental and habitual motives, then an independent $t$-test revealed that university place had a significant effect on Facebook instrumental motives for use ( $t=-$ 4.06, $\mathrm{df}=382, p=0.000)$, since Cairo University students $(M=7.9)$ use Facebook with instrumental motives more than Damietta University students $(M=7.5)$. There is also a significant effect for university place on Twitter instrumental use $(t=-1.9, \mathrm{df}=115$, $p=0.05)$, since Damietta University students $(M=6.5)$ are using it for instrumental purposes more than their Cairo University 
counterparts $(M=5.9)$. On the other hand university place did not have a significant effect on Facebook and Twitter habitual use motives. Nature of college was not found to have a significant effect on instrumental, habitual use of Facebook, and instrumental use of Twitter but it had a significant effect on habitual use of Twitter $(t=-2.6, \mathrm{df}=115, p=0.04)$, since Cairo University students $(M=5.5)$ use Twitter for habitual purposes more than their colleagues in Damietta University $(M=4.9)$.

We also found that residence place had a significant effect on Facebook instrumental use $(t=-4.06, d f=382, p=0.000)$, since students in city $(M=7.9)$ use Facebook more to gratify instrumental motives than village students $(M=7.5)$ but this kind of effect was not found in habitual use of Facebook while residence place affects both instrumental and habitual use of Twitter.

Three separate ANOVA tests were carried out and none of students' father educational level, students' mothers educational level, and SES had a significant effect on students motives of Facebook and Twitter use either these motives were instrumental or habitual.

H4.There is a significant relationship between importance of Facebook and Twitter importance in students' lives and their addiction to both of them.

This hypothesis has been proved according to data in the table below; since Pearson's correlation revealed a strong relationship between importance of both Facebook and twitter, and their addiction, see Table 2 .

H5. There is a significant relationship between Facebook and Twitter motives of usage and their addiction in students.

This hypothesis has been proved according to data in the table below, since Pearson's correlation revealed strong relationships between both Facebook and twitter habitual use and their addiction, $(r=0.495, p=0.000)$ for twitter and $(r=0.240$, $p=0.01$ ) while there are no significant correlation between Facebook and Twitter instrumental use and their addiction, see Table 2. 
Table 2 Pearson's correlations of study variables

\begin{tabular}{|c|c|c|c|c|c|c|c|c|c|c|c|c|c|}
\hline 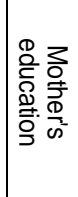 & 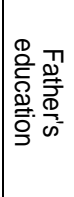 & 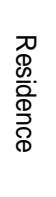 & 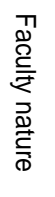 & 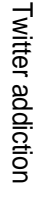 & 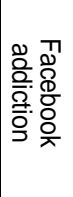 & 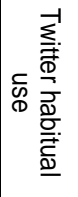 & 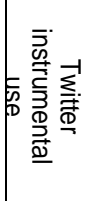 & 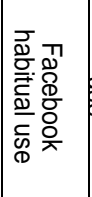 & 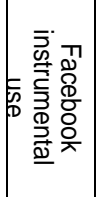 & 笕 & 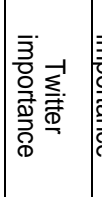 & 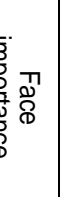 & \\
\hline$\dot{\omega}$ & $\dot{\mathrm{i}}$ & $\ddot{8}$ & $\stackrel{\dot{\vec{\sigma}}}{\vec{\xi}}$ & ָָ & 总 & $\overrightarrow{\omega_{\infty}}$ & $\grave{g}$ & \begin{tabular}{|c}
$\dot{w}$ \\
w \\
$*$
\end{tabular} & $\underset{\overrightarrow{\vec{\omega}}}{\overrightarrow{\vec{w}}}$ & $\dot{\infty}$ & 鯑 & $\rightarrow$ & 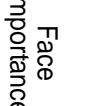 \\
\hline$\dot{\omega}$ & 竒 & $\varlimsup_{*}$ & $\dot{\Xi}$ & iٓ & $\tilde{\widetilde{\sim}}_{\sim}^{\sim}$ & \% & 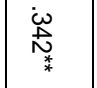 & \begin{tabular}{|l}
$\underset{\sim}{N}$ \\
$\vec{w}$ \\
$*$
\end{tabular} & $\stackrel{\grave{\omega}}{\omega}$ & : & & & 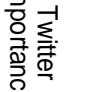 \\
\hline ஜू & $\underset{\ddot{q}}{\ddot{m}}$ & 愈 & $\dot{~}$ & $\frac{\dot{\sim}}{\vec{*}}$ & $\dot{\phi}$ & $\dot{\omega}$ & $\dot{\vec{े}}$ & $\dot{\bar{\omega}}$ & $\dot{d}$ & & & & 管 \\
\hline ๗ં & is & $\ddot{z}$ & $\dot{\omega}$ & $\dot{-}$ & $\dot{\omega}$ & $\dot{\grave{g}}$ & $\underset{\Downarrow}{\Downarrow}$ & in & & & & & 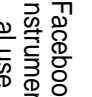 \\
\hline 点 & ìn & க் & ळ & 草 & 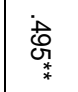 & 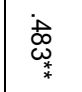 & $\overrightarrow{\mathrm{\omega}}$ & & & & & & \\
\hline ì & $\dot{\overrightarrow{\vec{\omega}}}$ & 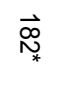 & $\dot{v}$ & 岕 & \&் & $\underset{\widetilde{W}}{\mathfrak{్}}$ & & & & & & & 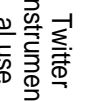 \\
\hline$\dot{\ddot{\omega}}$ & $\dot{\vec{\Xi}}$ & iq & $\overrightarrow{\dot{\mathrm{\alpha}}}$ & $y$ & 箈 & & & & & & & & 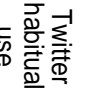 \\
\hline$\dot{8}$ & $\dot{\vec{\sigma}}$ & 䒫 & $\dot{9}$ & 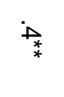 & & & & & & & & & 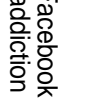 \\
\hline
\end{tabular}




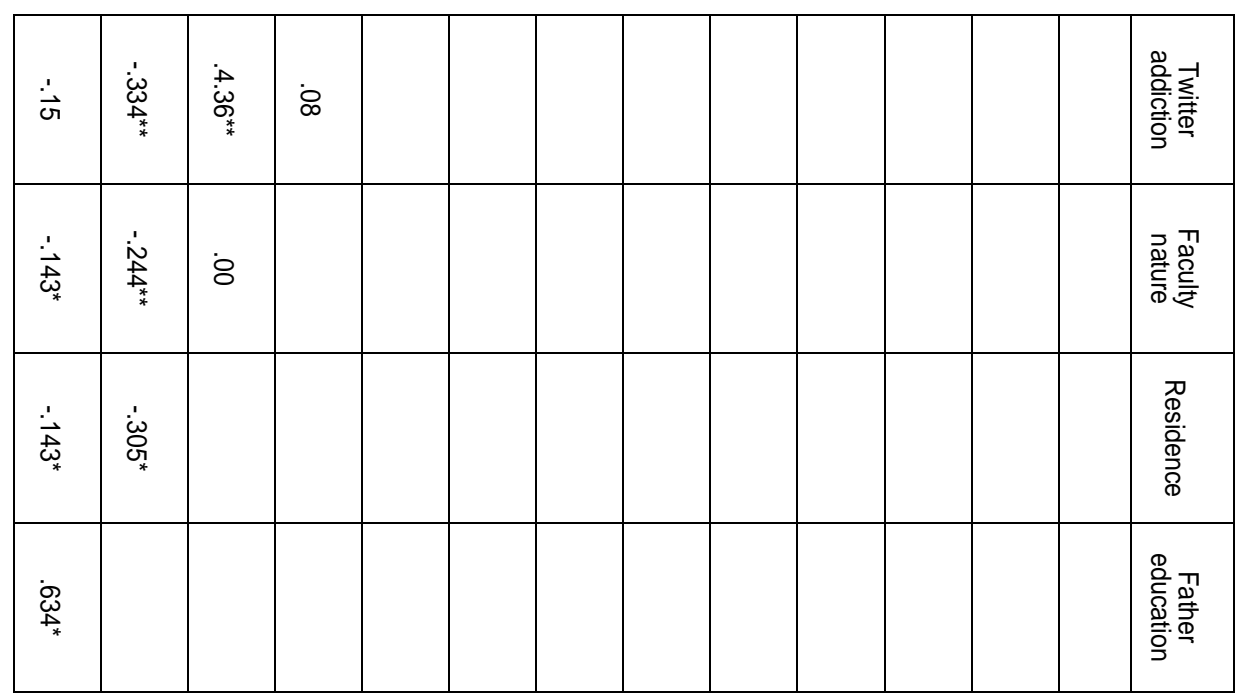

** Correlation is significant at the 0.01 level (2- tailed)

* Correlation is significant at the 0.05 level (2- tailed) 
H6. Students tend to perceive negative effects of Facebook and Twitter on others to be stronger than these effects on themselves (Third Person effect) while they tend to perceive positive effects of Facebook and Twitter on others to be weaker than these effects on themselves (First person effect).

This hypothesis was totally supported by using Paired sample $t$-tests as they revealed that students differ in perceiving negative effects of Facebook on others compared with on themselves $(t=-14.9, \mathrm{df}=383, p=0.000)$ as students tend to perceive less negative effects on themselves $(M=2.6)$ compared with these negative effects on others $(M=3.5)$, and the same result is true for perceiving Twitter negative effects $(t=-7.03$, $\mathrm{df}=116, p=0.000)$ and students tend to perceive less negative effects of themselves $(M=2,3)$ compared with these negative effects on others $(M=3.05)$. This result gives support for Davison's third person effect.

As for first person effect, it is also supported. Paired sample $t$-tests revealed that students differ in perceiving positive effects of Facebook on themselves compared with on others $(t=4.17, \mathrm{df}=383, p=0.000)$ as students tend to perceive more positive effects on themselves $(M=3.5)$ compared with these positive effects on others $(M=3.3)$, and the same result is true for perceiving Twitter positive effects $(t=3.8, \mathrm{df}=116$, $p=0.000$ ) and students tend to perceive less negative effects of themselves $(M=3.5)$ compared with these negative effects on others $(M=3.1)$. Thus first person effect was supported also.

\section{Discussion}

This study aimed at exploring the usage patterns of Facebook and Twitter among Egyptian female students in rural and urban areas and in relation to their demographics; students' motives and level of addiction to using such social media platforms and finally the student's perception on the negative effects and positive effects of Facebook and Twitter on their lives (Third Person effect) compared to others (First person effect). The findings of this study can be interpreted within the 
framework of the uses and gratifications theory as well as the $3^{\text {rd }}$ person effect theory.

It was interesting to see that Egyptian female students tend to use Facebook more than Twitter. While the majority of the students preferred using Facebook to Twitter, those who preferred using both platforms were more than those who preferred Twitter alone. Accordingly, it might not be surprising to find that Facebook users spend more time (an average of 2.8 hours a day) than those who use Twitter (average of 1.8 hours a day). These findings are consistent with (Abd-Elrazek, 2011; Mansour, 2011; Alheity, 2012; Mohammadein, 2012; Abdou, 2013; and Bahag, 2013; Hussein, 2014) as Facebook came ahead of Twitter in the list of SNS used among Egyptian university students. Taha (2011) also reported that $48 \%$ of Egyptian youth spent more than 2 hours daily on Facebook. However, the findings contradict Malin (2009) who reported that $50 \%$ of those surveyed in the MENA region used Twitter more than Facebook. This indicates that patterns of SNS usage among Egyptian female students might not be consistent with the patterns of SNS usage among youths in the MENA region.

Egyptian female students were also found to access Facebook and Twitter via their smartphones most of the time. However, it was surprising to see that the majority of the Egyptian female students would use their real identities and share more personal information such as their gender, photos, and age on Facebook compared to Twitter. This finding contradicts El-Sayed (2014) on reporting that Egyptian females were less likely to include personal information on SNS than males.

As for the activities carried out on Facebook and Twitter, it was refreshing to see that Egyptian female students would use Facebook and Twitter mainly to browse their newsfeed. They were also more likely to use Facebook for writing and receiving messages than they would on Twitter. Meanwhile, those who use Twitter would more likely use it to update their status compared to Facebook. Facebook users were also found to prefer following social pages more than Twitter users. Meanwhile, Twitter users preferred following political pages 
compared to Facebook users. It's worth noting that more than half of Facebook users preferred following religious pages while very few of Twitter users preferred following religious pages. This is consistent with Asaad (2011) on finding a relationship between Egyptian youths' usage Facebook and their societal values as life satisfaction and religiousness.

In light of the uses and gratifications theory, the study found that the students use Facebook and twitter for instrumental motives such as getting the news, learning about life and for research purposes more than habitual motives such as talking to friends, dating, and entertainment. In the same vein, students were found to use Facebook to maintain their existing relationships more than make new ones. This came in line with the findings of Taha (2011) that Egyptian university students use Facebook to communicate with friends in the first place, then joining different groups, and viewing pictures of friends on their walls followed. Meanwhile, our study found that Egyptian female students would use Twitter mainly to know others' political standpoint than expressing their own. Although pew research statistics show a majority of the surveyed in Egypt as using SNS to express their opinion on community issues, religion, and politics, our results lead us to conclude that Egyptian female students are less inclined to express their opinions on SNS than males.

While Asaad (2011) reported that most of the Egyptian youth found negative effects for Facebook including wasting time, pornographic content, trials of unwilling people to contact them, and some other social problems like cyber bulling and online fraud, our study found that Egyptian female students agree that Facebook and Twitter have more positive effects than negative effects. Female students agreed that both platforms mainly increase their knowledge of the happenings around them and on political issues as well as make them contribute in useful political and social activities. These findings are consistent with Hussein (2014) as he found that the majority of the Egyptian youth agreeing that using such networks affects positively on their political attitudes. Our findings are also consistent with Taha (2011) on reporting that students have 
more positive attitudes towards Facebook as it helps them to be aware of what is happening as well as communicate with their friends, and deepening the exist relationships.

Our study also found that students agreed that Facebook affects their lives on the following aspects in order. It affects their relationships with their families negatively, affects their academic performance positively, makes them have disorders in sleep or nutrition, and finally makes them have romantic relationships with the opposite sex. Students who use Twitter also agreed that Twitter affects their lives on the following aspects in order: their relationships with their families negatively, making them have sleep or nutrition disorders, affects their academic performance positively, and finally makes students have romantic relationships with the opposite sex.

The study found that physiological and psychological involvement mainly predicted students' addiction to Facebook followed by loss of time control, spending long hours, and negative academic performance. As for Twitter, the study found that losing the sense of time and preferring Twitter mainly predicted students' Twitter addiction, followed by using Twitter for long periods of time, adoring Twitter, and interest in Twitter activities.

The study hypothesized that the demographics of the students (academic approach of the schooltheoretical/practical, residence place city / village, educational level of students' parents, and students' socioeconomic status) have no significant effect on Facebook and Twitter use among students. The results found that some of the students' demographics had no effect on their usage of Facebook and Twitter. The results showed that Egyptian female students' usage of Facebook and Twitter was neither affected by the academic approach of the school practical/theoretical, nor their place of residence (city-village). These results came consistent with Alasdoudy (2012) findings, which showed that the academic approach of the school among Egyptian university students didn't affect their SNS usage.

The study also assumed that the demographics of the students have an effect on Facebook and Twitter addiction. The 
results showed that some of the demographics affected students' addiction to Facebook and Twitter. Students' who lived in the villages were also more addicted to Facebook and Twitter than their counterparts living in the city. Moreover, students whom their fathers hold high academic degrees such as Bachelor, Master or Ph.D. were more addicted to Facebook and Twitter than students whom their fathers are of other educational levels. However, the educational level of the students' mothers had no effect on the students' addiction to Facebook or Twitter. Also the socioeconomic status of the students had no effect on the students' addiction to Facebook; however students of low and middle socioeconomic status were more addicted to Twitter than students of high socioeconomic status. Moreover, the study found that there is a relationship between importance of Facebook and Twitter in students' lives and their addiction to both of them.

This study also hypothesized that the demographics of the students will affect students' motives to use Facebook and Twitter. Students living in the city use Facebook more to gratify instrumental motives than students living in villages. On the other hand, students' fathers educational level, students' mothers educational level, and students' socioeconomic status had no effect on students motives of Facebook and Twitter use whether these motives were instrumental or habitual.

In terms of first person effect, most of Facebook and Twitter users consider that these two platforms have more positive effects on themselves than others. In this study we assumed that students tend to perceive negative effects of Facebook and Twitter on others to be stronger than these effects on themselves (Third Person effect) and that they would perceive positive effects of Facebook and Twitter on others to be weaker than these effects on themselves (First person effect). The findings supported the third person effect theory as the students perceived Facebook and Twitter as having less negative effects on themselves compared to others. In addition, the study supported the first person effect theory, as the students perceived that Twitter and Facebook have more positive effects on them compared to others. 


\section{Limitations of the study}

Although this study found some intriguing results on the SNS use among Egyptian female students, there have been some limitations. While we found that students who lived in villages were more addicted to using Twitter and Facebook than their counterparts who lived in the city, it is worth taking into consideration that they used these sites with instrumental and habitual motives as they had no alternatives compared to their peers who lived in the city. Therefore, the results on Egyptian female students' use of SNS in relation to their place of residence should be applied with caution.

This study also aimed at incorporating the effect of the location of the university whether its village-located (Damietta University) or city-located (Cairo University), however, we decided to eliminate the results of this part from the study to avoid.

\section{Conclusion}

In this study we can conclude that Egyptian Female students prefer using and spending more time on Facebook compared to Twitter. Moreover, Facebook was mainly used for for engaging in social and religious - related issues but seem to keep Twitter for all what relates to political-related matters.

In addition, Egyptian female students whether in cities or in villages were found to use their real identities and share personal information on Facebook more than Twitter? This might raise a question if they are less inclined to do so on Twitter in fear of revealing their identity being that they their use of Twitter is mainly for political-related issues.

Although, Egyptian female students find that SNS have more positive effects than negative effects, they find that they have some downsides such as affecting their relationships with their families negatively and causing them to have sleep or nutrition disorders. This could be explained by the ways they are addicted to such platforms. For instance, we find that physiological and psychological involvement was the main indicator of students' addiction to Facebook followed by other indicators. 
We can also find that the students' who lived in the villages were also more addicted to Facebook and Twitter than their counterparts living in the city but this might be due to the lack of other resources to them than their counterparts living in the city. However, Twitter addiction was only seen among students of low and middle socioeconomic status compared to high socioeconomic status' students.

The third person effect theory is clearly applicable in the case of the Egyptian female students' and their use of SNS. The students perceived that Facebook and Twitter have less negative effects on themselves compared to others while perceiving that the same platforms have more positive effects on them compared to others (first person effect). 


\section{References}

Abd-Elfattah, A. (2012). The new mass communication: A version from sites of communication behaviors of Muslim Brotherhood youth before and after $25^{\text {th }}$ January revolution. A paper presented to Mass Communication Faculty at Canadian university in Egypt on The future of Mass Communication after Arabic revolutions.

Abd-Ellah, A (2011). Effective factors in Arabic girl Internet usage: Comparative socio mass communication study on Egyptian and Saudi girls. Egyptian Journal of Mass Communication Research, 37, 75-120

Abd-Elrazek, G. (2011). Sites of SNSs as media for youth to acquire self learning skills and civil participation. Egyptian Journal of Mass Communication Research, 10(7) 237-299.

Abdou, k. (2013). Youth relationships with sites of alternative ass communication on Internet. MA thesis, Mass Communication Faculty. Cairo University.

Alheity, M. (2012). SNSs and political changes in Egyptian society: A study on Egyptian youth. A paper presented to $18^{\text {th }}$ conference of Mass Communication Faculty Cairo University on Mass Communication and building the new society.pp.13-114.

Alasdoudy, N. (2012). Role of SNSs in youth's perception of opinion freedom and political participation in $25^{\text {th }}$ January revolution. MA thesis. Mansoura University. Mass Communication Department.

Asaad, A. (2011). The relationship between Egyptian youth usage of SNSs and their societal values: A study on YouTube and Facebook. PhD dissertation. Cairo University. Mass Communication Faculty.

Bahag, A. (2013). Arabic youth usage of SNSs. MA thesis. Institute of Arabic research and studies. Department of media studies.

Davison, W. P. (1983). The third-person effect in communication. Public opinion quarterly, 47, 1-15.

El-Sayed, Y. (2014). Interactive communication through SNSs and its relation with social capital. MA thesis. Mass Communication Faculty. Cairo

university.

Hassan, A. (2009). Effects of SNSs and space TV channels on Egyptian and Qatari family communication patterns: comparative study on youth and parents in the light of alternative mass communication. A paper presented to the first scientific conference on Family, Communication, and the challenges of the age.pp.287-317.

Hassan ,A.(2012). Role of social networks in forming public opinion in Arabi Society towards Arabic revolutions. A paper presented to $18^{\text {th }}$ conference of Mass Communication Faculty Cairo University on Mass Communication and buildig the new society.pp.387-436.

Hussein, G. (2014). Role of SNSs in developing political awareness: A case study on $25^{\text {th }}$ January revolution youth. MA thesis. Institute of educational studies. Cairo University.

Kilany, H. (2007). Internet effect on traditional media in Egypt. Egyptian Journal of Public Opinion Research,8(2) 1-68.

Kuss, D. J., \& Griffiths, M. D. (2011). Online social networking and addiction-a review of the psychological literature. International journal of environmental research and public health, 8(9), 3528-3552.

Mansour, M. (2011). Effects of university students' youth Facebook usage. Egyptian Journal of Mass Communication Research,37,175-228. 
Mohammadein, A. (2012). Role of SNSs in directing public opinion to political events in Egypt : A case study onn presidential elections. A paper presented to $18^{\text {th }}$ conference of Mass Communication Faculty Cairo University on Mass Communication and building the new society.pp.647-732.

Paradise, A., \& Sullivan, M. (2012). (In) visible threats? The third-person effect in perceptions of the influence of Facebook. Cyberpsychology, Behavior, and Social Networking, 15, 55-60.

Paul, B., Salwen, M. B., \& Dupagne, M. (2000). The third-person effect: A metaanalysis of the perceptual hypothesis. Mass Communication \& Society, 3, 5785.

Salem, F., Mourtada, R., Al-Dabbagh, M., \& Gargani, G. (2011). The Role of Social Media in Arab Women's Empowerment. Arab Social Media Report, 1(3), 1-26. $\begin{array}{llll}\text { Retrieved } \quad \text { 21, 2015, from } & \text { 20 }\end{array}$ http://www.arabsocialmediareport.com/UserManagement/PDF/ASMR Report 3.pdf

Schweisberger, V., Billinson, J., \& Chock, T. M. (2014). Facebook, the Third Person Mediated Effect, and the Differential Impact Hypothesis. Journal of Computer Communication, 19, 403-413.

Taha, A. (2011). Egyptian university students usage of SNSs and its relation to social capital: A study applied on Facebook. Egyptian Journal of Mass Communication Research, 10(4) 103-147.

Young, K. S. (1998). Internet addiction: The emergence of a new clinical disorder. CyberPsychology \& Behavior, 1(3), 237-244.

Wang, C., Lee, M. K., \& Hua, Z. (2015). A theory of social media dependence: Evidence from microblog users. Decision Support Systems, 69, 40-49.

Zakareya, N. (2009) social and psychological effects of Egyptian students usage of SNSs. A paper presented to the first scientific conference on Family, Communication, and the challenges of the age. pp.1-78. 